\title{
Is Indian Education System Ready for Digital Transformation
}

\author{
Anup Sharma1, Jenith Gajera', Rajkumar ${ }^{2}$, Omkar $^{2}$, Pawan $^{2}$ \\ 1Assistant Professor, Lovely Professional University \\ 2MBA Scholar, Lovely Professional University
}

\begin{abstract}
:
The novel coronavirus has changed the entire perspective of education for the world. To follow the rule of social distancing and to prevent getting gathered at one place in a large number of people the educational institutions from all over the world have given holidays. Initially, no one knew that this time the pandemic would have long-term effects and hence all the educational institutions have begun their curriculum through online mode. As this is a huge step towards technology and this cannot happen overnight the educational institutions are using the already available sources for example Google meet, zoom meeting, Google classroom, etc. while some of the institutions who are advanced in technology have created their applications and websites for their curriculum. And taking advantage of this situation now the software companies are offering schools, colleges their support for creating online portals for education. Online education can be effective in digitally advanced countries because they would have all the necessary tools for the purpose while the other countries will suffer in this area. Due to this number of problems were encountered. Where there are several negative impacts on the education sector throughout the world there is also a very big positive impact that the entire educational sector is becoming digital. The process which would have taken a decade to be formed is happening in just a small time only due to this crisis. The next year might not be the best for the education sector and that is an undeniable fact but the rest of the upcoming years after that will be the future and a lot of advantages would come from that. From the student's perspective right now they are facing issues with almost everything in their schools/colleges although the staff is trying their best to tackle the situation there is a lack of resources and tools to do so. In these crucial times, the government has stepped forward and will help in the formation of the new educational system where everything will be digitized and fulfill the needs of the traditional system adding more benefit to the same.
\end{abstract}

\section{Keywords: Digital Transformation,}

\section{Introduction}

Technology has fundamentally transformed education. For one, technology has massively increased access to education. Books were scarce in medieval times and only a few elites had access to educational possibilities. People had to go to learning centers to study. A significant amount of material (books, audio, photos, videos), and formal education resources can be accessed online via Khan Academy, MOOCs, podcasts, standard online programs, and more. Today there is a lot more information accessible to anyone through the Internet. Today's proximity to learning opportunities is unprecedented by technology.

Technology has since increased the chances of connectivity and cooperation. Classrooms are traditionally relatively segregated and collaboration in the same classroom or building is confined to other students. Today, technology makes unrecognized modes of connectivity and cooperation. Students in the U.S. rural classroom, for example, can learn about the Arctic via expeditions with a team of local scientists, read science blog posts, view images, send email questions to researchers and even chat live through videoconferencing to scientists. Students in other countries that track the same expedition will discuss what they learn in other classrooms. Students may work using technology-based platforms such as wikis and 
Google Docs to help community projects. The walls of the classrooms no longer form an obstacle, as technology allows new ways to read, interact, and collaborate.

The implementation of previous policies on education focused primarily on access and affordability issues. This legislation adequately tackles the unfinished agenda for the 1986 National Education Policy, revised in 1992 (NPE 1986/92). The Right of Children to Free and Compulsory Education Act 2009, which set down legal bases for universal basic education, has been significant development since its last program of 1986/92.

The National Education Policy 2020 is the century education policy that aims at solving our country's many rising barriers to growth. This strategy seeks to examine and revamp all facets of the educational process, including its legislation and governance, to develop a modern framework aligned with the aspirational objectives of education in the 21 st century, like SDG4, while developing on India's traditions and value systems. The National Education Strategy stresses the development of each individual's artistic ability. The idea is that schooling must not only improve cognitive ability the "founding skills" of literacy and numeracy and cognitive skills "higher order," like logical reasoning and problem-solving but also psychological, spiritual, emotional capabilities, and dispositions.

With the Covid-19 pandemic already closed classrooms, children expend long hours on laptops and cell telephones for online classes, so parents start to think about headaches, eye problems, and stress. For preprimary students just 30 hours of screen time, two 45 minute classes for classes 1-8, and four 45 minute classes for classes 9-12, are suggested by the Ministry for Human Resource Development (MHRD), but parents complain that it is not working. Lessons frequently run until the evening after the children are expected to complete their homework. Parents decide to rest for 10 minutes and wash their eyes for the children, but their eyes are still rotting, which as a parent is truly alarming. Any parents still pose questions around mental health as children today have greater mood fluctuations related to the use of electronics. They are still co-operative and anxious at home. At home.

On the other hand, some of the positive effects had also been done on student life through online teaching. Most students have bulky school packs, contain books, copies, and plenty of conventional school supplies that must be on their own every day of school, daily work of this nature has resulted in shoulder-pain, it is not the compatibility of small children with well-being. It has detrimental health consequences. But the training online provides you with all of the lectures, you don't have to go anywhere, you just have to sit in the room and study from the laptop face to face.

\section{Literature Review}

\section{Online learning amid the COVID-19 pandemic: Students' perspectives}

The novel coronavirus has changed the entire perspective of education for the world. To follow the rule of social distancing and to prevent getting gathered at one place in a large number of people the educational institutions from all over the world have given holidays. Initially, no one knew that this time the pandemic would have long-term effects and hence all the educational institutions have begun their curriculum through online mode. As this is a huge step towards technology and this cannot happen overnight the educational institutions are using the already available sources for example Google meet, zoom meeting, Google classroom, etc. while some of the institutions who are advanced in technology have created their applications and websites for their curriculum. And taking advantage of this situation now the software companies are offering schools, colleges their support for creating online portals for education. Online education can be effective in digitally advanced countries because they would have all the necessary tools for the purpose while the other countries will suffer in this area. Due to this number of problems were encountered. Where there are several negative impacts on the education sector throughout the world there is also a very big positive impact that the entire educational sector is becoming digital. The process which would have taken a decade to be formed is happening in just a small period only due to this crisis. The next year might not be the best for the education sector and that is an undeniable fact but the rest of the upcoming years after that will be the future and a lot of advantages would come from that. From the student's perspective right now they are facing issues with almost everything in their schools/colleges although the staff is trying their best to tackle the situation there is a lack of resources and tools to do so. In these crucial 
times, the government has stepped forward and will help information of the new educational system where everything will be digitized and fulfill the needs of the traditional system adding more benefit to the same.

\section{Factors affecting cloud computing adoption in the Indian school education system, Jewan Singh, Vibhakar Mansotra;}

As IT-enabled facilities become increasingly costly, Cloud computing has emerged as a major alternative platform that provides improved reliability, scalability, versatility, accessibility, and throughput processing. Because of its operational and cost-effective advantages, the focus on cloud computing has increased manifold, enabling public and private sectors to implement solutions within very short periods without building massive infrastructure and wasting enormous efforts and resources on implementation against existing applications. In India, up to senior secondary level, over 150 million students were enrolled during 2015. However, India's literacy rate is around 74 percent and it still lags 84 percent behind the world's average literacy rate. Because of the early responses by establishing a technology Centre or a dedicated building for house computers and peripherals to provide data access to the computer, the impact of information and communication technologies (ICTs) has influenced primary and secondary education worldwide. According to this case study, a theoretical model based on the TOE paradigm is proposed to clarify the role of technical, organizational and environmental factors in the Indian school education system in the adoption of cloud computing.

The findings show that relative benefit, compatibility, and sophistication are of relative benefit. Representing technical factors; top management support representing organizational factors; and a positive and important effect on the adoption of cloud computing services in the Indian school education system was found to be competitive pressure, external knowledge, and attitude towards change representing environmental factors. The results are of great importance as they can provide knowledge of cloud computing variables, as well as insights and guidance to educational policy planners and decision-makers for the successful adoption of cloud computing technology in India.

Nevertheless, the apparent increase in the integrated use of technology is still a range of problems facing the school education system, such as pressure to reduce costs, intense rivalry, difficulty managing knowledge and retaining a competitive edge through development and diversification. With these new challenges, dayto-day access to information and related resources without geographical barriers is growing.

\section{Quality problems of engineering education programs in India, K.G. Viswanadhan;}

Technology has a more direct effect on the nation's wealth creation, more than any other discipline. Therefore, the education and training of technologists and engineers are of great importance in a technologically intensive society and are regarded as critical requirements. The level of education earned by engineers would have a direct effect on how businesses compete and contribute to the global economy where they are employees. Technological progress in the modern economy is essential to the development of wealth and economic growth. To retain a competitive edge, engineers need to be enablers of wealth creation rather than merely being a global market product. The pressures for a broader and enhanced selection from a range of stakeholders, Many international universities are currently facing the challenges of reorienting their approaches to be more customer-focused and performing their operations in a more business-like manner of services from the higher education sector along with a simultaneous increase in pressure on resource utilization.

Such reforms have also had an impact on the Indian engineering education system. There is a perception, along with many success stories, and there is enough evidence and reasons to do so, that science and technology are on the downward path in India, and standards in science \& technology education are declining at a rapid pace as young people's intellectual level is rising.

The first stage of the analysis will be to identify a set of quality metrics that can be best used to measure the performance of an engineering program. As institutions explore innovative ways to provide educational opportunities, education is undergoing a technological transition. Organizations will more efficiently reengineer their learning programs by setting and upholding requirements. The quality of education is a multidimensional term and can be seen as a combination of the quality of the education system's input and output method. The variables that affect the success of engineering education. Some of them are teaching procedure, cooperation between the university and industry, management position, student intelligence and interest, teacher excellence, accreditation standards, e-education, etc.

Technology-Enhanced Learning in Developing Nations: A review, Shalni Gulati; 
The Internet is also seen as a value-neutral instrument that enables people to transcend conventional elitist space constraints and gain unhindered access to learning. Online technologies are commonly proposed to help tackle problems of educational equality and social exclusion and to open up democratic and affordable educational opportunities. Government organizations that support education efforts in developing countries have promoted the use of emerging technology to reduce the expense of reaching and educating significant numbers of children and adults who still lack education.

New communication technologies, especially the Internet, seem to offer exciting opportunities to overcome geographical access and cost-effective learning barriers. However, it is difficult to believe that such innovations will have a significant effect on the education of children and adults who lack basic livelihoods and live in an underdeveloped educational infrastructure.

This paper discusses the developments in open and distance learning in developed countries and asks if these developments address education in developing countries. The discussion highlights the challenges raised by poverty, the lack of social and educational infrastructure, and cultural problems that are constraining the development of education in developing countries.

This paper discusses the conundrum that, on the one hand, learning technologies (i.e. print, radio, television, film, audio, telephone, computers, and the Internet) are seen as a solution to the limitations and rigidities of traditional education since they meet a greater number of learners, On the other hand, the challenge of accessing these technologies and the digital divide between wealthy and disadvantaged communities continue to deepen the education gap where these technologies are used.

\section{Information and Communication Technology in Higher Education in India: Challenges and Opportunities, Uttam Kr Pegu;}

Not only has the advent of ICT radically changed the activities of companies and management, but also education. While the world is moving rapidly towards digital media, the role of ICT has become more and more important in education. The sudden information technology boom has been that way the information is disseminated today has been changed. The way, how teachers connect and communicate with students and vice versa is the way it has one of the major changes. The fact that the problems of insufficient access to technology and inequity coupled with economic considerations and technical know-how are plaguing, higher education in India remains to be seen how information and communication technology can burgeon students and how it can encourage progress in this aspect. India's emancipatory and disruptive ICT capacity in higher education has helped to increase the country's higher education requirements through part-time and distance learning systems. It can be used as a tool to address cost problems, fewer teachers, and low educational quality, as well as to overcome obstacles to time and distance. ICT-based education can provide greater data collection reliability, validity, and productivity and greater ease of review, assessment, and interpretation at any educational level.

There is an increasing concern that ICT will transform India into an information society, but can technology alone improve the standard of higher education in the country? The penetration of ICT systems in higher education institutions is extremely poor, according to a 2008 UGC survey of accredited colleges, which indicates gaps in the IT infrastructure. Since most Indians living in rural areas have limited internet connectivity, they need to be introduced to and educated in basic computer skills and the use of ICT. Also, a low understanding of IT literacy is a major challenge facing India in achieving the implementation of ICT in higher education. Most government agencies do not have appropriate IT systems, as stated by the Internet and Mobile Association of India (IAMAI).

The linguistic diversity of India needs the creation of content in various forms of Languages to improve applications for ICT. The rural-urban ratio is 68.84 percent and 31.16 percent in terms of population, where the majority of rural people do not speak English, according to the 2011 Census. The need to produce content in all of India's official languages is therefore becoming all the more relevant.

\section{Distance education and the role of IT in India, Siriginidi Subba Rao;}

Teaching and learning are no longer limited to the school day or the classroom. For more than a century, distance education (DE) has existed. Until recently, DE was considered by many individuals to be unorthodox and peripheral, and the sheer distance between teachers and students made teaching and learning not only inefficient but often counterproductive. The developments in communications and knowledge networks have been strengthened and Demolished physical distance barriers and other intrinsic shortcomings in DE. Over the last two decades, DE has made tremendous progress and has now gained 
widespread recognition as a viable alternative distribution method and an alternative to the traditional system. The rapid growth of IT, computer literacy and internet access provide enormous possibilities for DE and training to be provided online. The web-based real-time classes on the internet are a matter of fact and the virtual university is no longer fiction. Learning is influenced by the introduction of information and communication technology to connect teachers and students in real or delayed time or on a need-based basis, and content delivery can be accomplished by the incorporation of various techniques, including audio, video, screen, internet, multimedia, satellite, TV, cable TV, interactive video, electronic telephone line transmissions.

Distance learning needs to be used to resolve the issue of insufficient educational materials and services for use in various parts of the world in a significant way. Leveraging primarily IT, communications and broadcasting is the best way to provide quality education to the masses cost-effectively. Learners are far removed from their instructors in distance education and lessons are imparted by multi-media approaches. Therefore, a fundamental necessity for fulfilling this void is the function of libraries. In general, distance learners need a certain library and knowledge resources, such as the loan of a particular text or reference book; photocopy for their course of a particular journal article or single section of a book or previous review papers; knowledge/material on a specific subject.

Sharing knowledge is vital to the process of raising expectations for education. If organizations are interconnected through IT-enabled networks, they would be able to more effectively exchange knowledge and thus quickly raise standards.

Transforming universities in interactive digital platform: case of City University of science and information technology, Muhammad Nauman Habib \& Waseef Jamal \& Uzma Khalil \& Zunnoorain Khan;

The goal of this study was to understand the automation of Higher Education Institutes (HEIs) and to analyze the automated process from the perspective of developing countries. This study identified few automated system functions that are rarely used, as well as few duplications and operational activities that require management consideration.

The case of CUSIT proves to be a real case for all those universities that face difficulties due to the pandemic of the coronavirus and are searching for a solution through distance learning and e-learning platforms to continue education. This study promotes HEI automation and offers lessons learned by defining performance characteristics as well as device shortcomings for academia and HEI management. As information is developed and disseminated by Higher Education Institutes (HEIs), an integrated and technology-driven framework is therefore effectively instrumental in the learning and success of research activities. ICT, therefore, serves from this point of view as an effective and essential tool for HEIs in the development and dissemination of information. The above practices, which are stable and effective academic programs, play a crucial role. Significantly, the emphasis is on university library automation, although many other co-integrated and associated activities that take place concurrently are overlooked. A traditional approach based primarily on manual activities is considered non-interactive, so ICT-enabled systems can, however, demonstrate improved communication between faculty, students and administration, which can, for its part, assist HEIs

Computer technologies have driven institutions to bring fundamental change to their methods by delivering higher education. Some influences are assumed to be propelling agents in the adaptation of ICT to HEIs, which can therefore be demonstrated by various methods. These factors include the adaptation of the new technology, the interactive learning environment, the rise in internet use, and the availability of online tools. Such integrated technologies were found to be constructive in support of the Academics assist students in learning key skills ( e.g. communication, analytics, teamwork, innovation, etc.) in the form of subject areas, and help build a bridge between instructor, student, and leadership.

Operationally, the device is capable of being updated and enhanced to be further enhanced as necessary. There are, however, few external factors (external bodies' regulations) that prevent HEIs from being paperless, otherwise, they would have become environmentally friendly and completely digitalized.

Computers and Productivity: Evidence from Laptop Use in the College Classroom, Richard W. Patterson, Robert M. Patterson; 
Computers can increase educational efficiency dramatically. Computers allow students to connect with educational software, take better notes, more easily complete assignments, remain more organized, and access a wide range of learning tools instantly. However, with the rise in the number of internets and computer-based distractions. If students are adequately available, Susceptible to computer use-related distractions or other unproductive activities, then the cost of computer use can outweigh the benefits. As the use of computers in the classroom becomes widespread, it is increasingly important to determine whether computers assist or hinder the performance of students and what policies can lead to improved student results. Despite the important role computers play in the classroom and the low cost of enforcing computer policies in the classroom, very little is understood about how computer usage affects the productivity of students.

Computer use is even greater in newer research. In our research, we found that $72 \%$ of students in the classroom use laptops, and Carter et al. Found that $79 \%$ of students use laptops. 1 Also, the effectiveness of classroom learning is becoming increasingly relevant as the ratio of class to research time has increased to the point that the average college student spends more time in the classroom than studying outside it.

Over the past 50 years, the time students spend outside the classroom studying each week has decreased precipitously from 24 hours in 1961 to just 11 hours in 2004, with the classroom every week staying roughly constant at around 16 hours a week. Equity considerations also promote a review of the influence of computer usage in the college classroom. African American and Hispanic students are less likely to purchase computers, as are those from economically disadvantaged backgrounds.

In this paper, we present quasi-experimental proof of the effect on academic performance of computer usage in college classrooms. This research takes advantage of a college policy that requires all students to own a laptop computer but allows individual teachers in their classrooms to require, authorized, or prohibit computers.

\section{The role of information and communication technology (ICT) in mobilization of sustainable development knowledge: a quantitative evaluation, Mirghani Mohamed, Arthur Murray and Mona Mohamed;}

In the global socio-technological domain, ICTs play a vital role by Information mobilization, network externalities, partnerships, and relationships with "cooperative" Recent developments in technical ubiquity, semantics and information representation have increased the integration of Knowledge Management (KM) systems, ICT infrastructure and architecture. For the promotion of sustainable development, the role of ICTs in advancing awareness and human development should be central.

Many scholars, as well as development organizations, have recognized the value of ICTs for sustainable development, with particular reference to their role in reducing time limits and geographical remoteness. In addition to providing communication, processing and storage, the modern ICT infrastructure must integrate cooperation and collaboration capabilities into its core architecture. Inherently intricate and often contentious is the relationship between ICTs and economic development. However, it is widely believed that information is important for socio-economic and socio-technical growth within the "knowledge-based economy" sector since it generates knowledge that is essential for sustainable development. Significant attention is given to the link between ICTs and economic growth by various practitioners within organizations. Technology, however, was only treated as a tool for low-level communication and collaboration and appeared to be abused rather than used within organizations for KM purposes.

The transition to a "knowledge-based economy" and progress towards sustainable development requires a shift in our perception of how to use ICTs to address the implicit economic-development dispute. ICTs designed without KM concepts in mind could impede their status as the best modus operandi for geographically dispersed sustainable development initiatives due to several intermingling factors.

ICTs help companies transition from functional approaches to process-oriented ones. But this involves a radical shift in the system components' configuration and behavior. To synergistically reach decisions, it is time for decision-makers in the international development arena to engage in information creation and consider the holistic framework thought beyond technology.

There are several ways to minimize the impact of ICT on knowledge dilution by either using updated smart technology focused on web services, natural language, artificial intelligence, or encouraging contributions to humanistic cognitive behavior through face-to-face modalities such as conferences, workshops, working groups, etc. 


\section{Objectives}

1. The objective of our study was:

2. To identify factors affecting student experience with online teaching systems.

3. To identify the factors affecting workload pressure on educators.

4. To identify factors affecting Digital transformation.

5. To identify factors affecting the teaching efficiency of educators.

\section{Proposed Methodology}

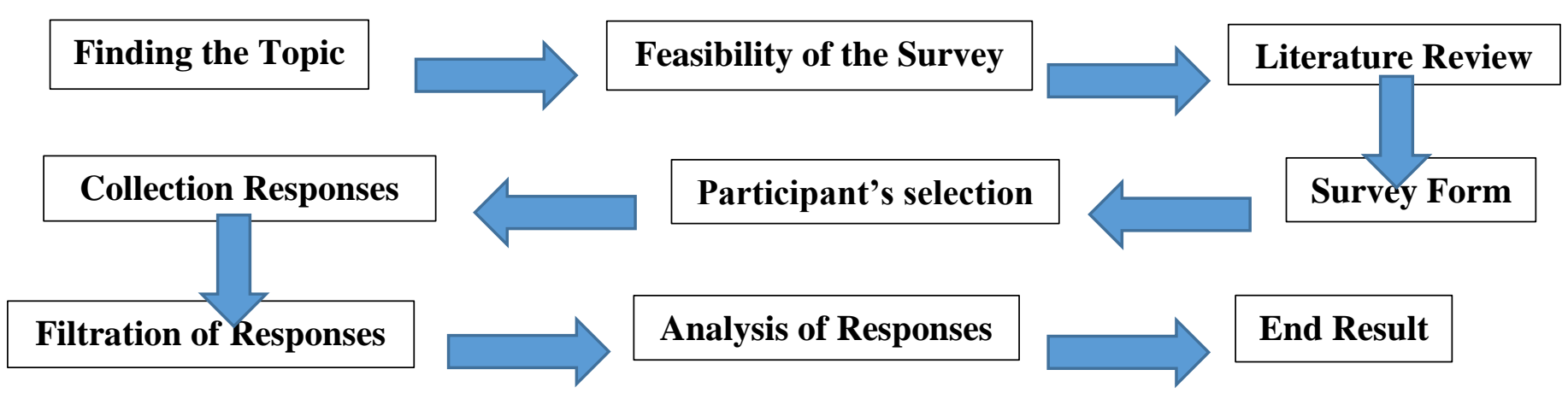

The education system has changed online in recent times due to Covid-19. So some many Universities and schools were unable to turn themselves into an online mode, so we took it as a Topic and tried to find that the education sector is prepared for digital transformation? We check the feasibility of the survey after selecting the topic and post that we prepared a literature review where we checked for several research papers and articles on related topics.

Research work includes primary data and secondary data where primary data is obtained through convenience sampling in which a group of individuals have been identified and asked for responses. On the other hand, by reviewing several research papers reading some articles of the well-known site, and even visiting some official site of the government, secondary data is obtained.

Research work is essentially divided into two distinct parts: exploratory research and focus research. We conducted exploratory research among the participants of the Focused Group Discussion (FGD) and collected the data. On the other hand, as part of an oriented study, we have conducted surveys based on the questions that were obtained using FGD. A quantitative method is chosen where a study is being conducted among students and teachers to obtain their views. The survey questioner includes open-ended questions as well as some closed-ended questions where we have tried to find out about problems faced by students and teachers during the online mode of study. The purpose behind the open-ended question is to get a point of view and we have also included several examples in the survey where we suspect that participants would be misled. The survey involves nearly 230 pan-Indian participants who are mostly teachers or students.

After gathering the survey results, we have filtered them out and picked some popular feedback and issues faced by teachers and students. We have gone to the solution segment after evaluating the problems, where we have tried to solve the problems and find solutions for them, and we have also found that is India is ready for online education.

\section{Data Analysis \& Conclusion}

\section{Response Category:}

* In this digital survey, $76 \%$ students and $24 \%$ teacher has participated, it's like a good percentage of participation in this survey.

* This survey has followed a perfect ratio 3:1 means, one teacher response for three students.

* This survey data has been collected from most of the part of Indian universities/ colleges Faculties and students.

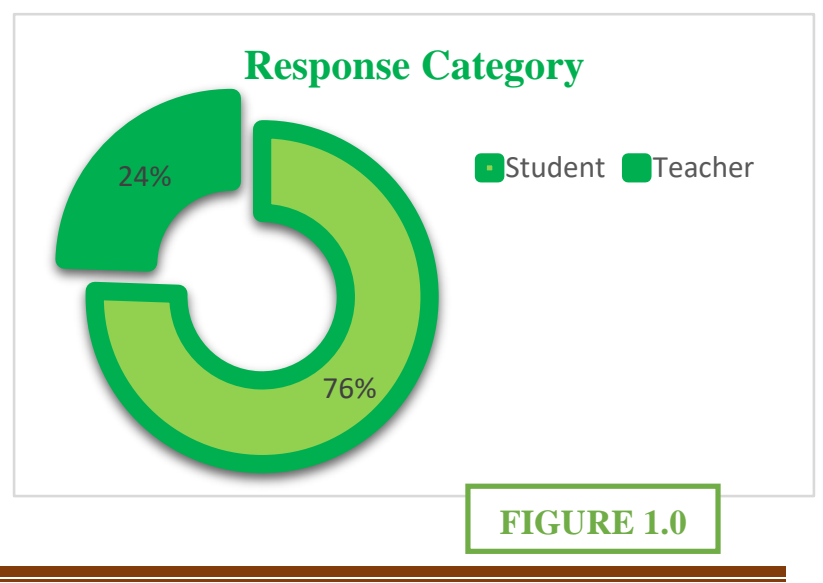




\section{Common problems in using online mode by students:}

Data in the graph is showing problems in using online mode by students, which are mention below...

* According to this graph, $31.21 \%$ of students faced communication problems with the educator in online mode and $28.90 \%$ of students faced problems in understanding concepts.

* $17.92 \%$ of students have faced both the problems like understanding concepts and communication and $10.40 \%$ of students faced other issues.

* $6.36 \%$ of students faced internet connectivity problems, maybe they live in rural/hilly areas or sometimes network issues, $2.89 \%$ students said NO PROBLEM and $2.31 \%$ students faced Interaction Problem in online mode class.

\section{Study Material provided by the institute:}

Data in the graph are showing "Study Material Provided by Institute" and the data is also showing that most of the students in this pandemic, how to get attraction towards PDF, PPT, Text Book PDF and Articles etc.

* According to this graph, $93.06 \%$ of students are like study online with study material Soft Copy (pdf, PPT, Text Book) and only $1.73 \%$ students still like Hard Copy of the textbook during the online study.

* $2.89 \%$ students like both of the material Soft copy (pdf, PPT, textbook), as well as Hard copy of text book and data, is also showing that $0.58 \%$ students like to prefer only Soft Copy(PPT).

Relevance: There is lots institute in India which are provided online study material for students during the lockdown period, which is mentioned below...

* SWAYAM Online Courses (https://swayam.gov.in/about) Quality learning material earlier available on the SWAYAM platform.

* UG/ PG MOOCs (https://ugcmoocs.inflibnet.ac.in/ugcmoocs/moocs_courses.php ) Hosts learning material of SWAYAM for UG and PG (Non-Technology) archived courses.

* E-PG Pathshala (https://epgp.inflibnet.ac.in/) Offers top-quality online content (e-text and videos) in 70 PG courses like Social Science, Arts, Humanities, Fine Arts, Mathematics through 23000 modules.

* E-Content courseware in UG subjects (http://cec.nic.in )

* Engineering E-books (open access): http://www.e-booksdirectory.com/engineering.php

Universities are now using innovative strategies to ensure continuity of education for their students. Professors are using online educational platforms, videoconferencing software like Google Meet, Zoom, and Microsoft Teams, help in organizing online lectures and discussion sessions, and social media to teach their course. Online educational platforms, like Google Classroom and Blackboard, allow professors to share notes and multimedia resources related to their courses with students. The online educational platforms also allow students to turn in their assignments and professors to keep track of the progress of the students. 


\section{Marks Bifurcation:}

Data in the graph are showing Marks Bifurcation which is mention below

* According to the graph, it is clear that $26.01 \%$ of student are evaluated by class test, Attendance and assignments in the online mode of education and $20.23 \%$ of students are evaluated by Attendance only

* $19.08 \%$ of students are evaluated by Assignment, $16.76 \%$ are evaluated by Attendance and Assignments and $6.94 \%$ of students are evaluated by other means of evaluation

\section{$50.00 \%$ \\ Marks Bifurcation}

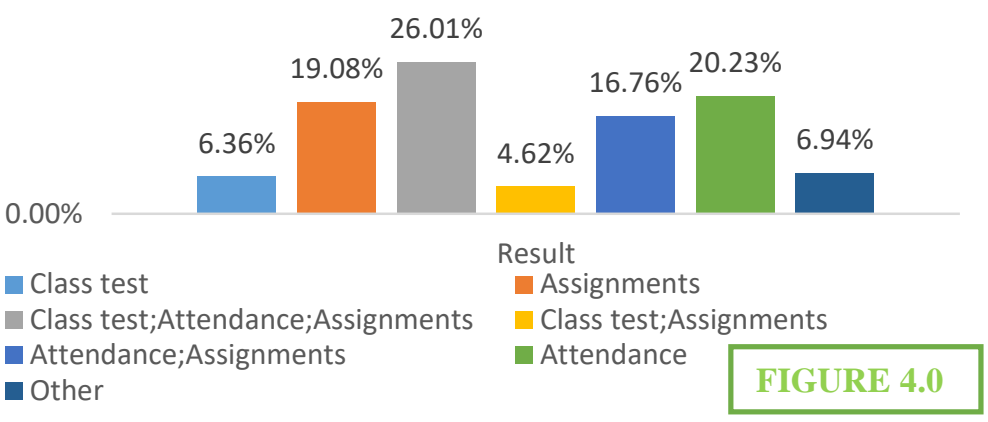

* $6.36 \%$ students are evaluated by class tests and $4.62 \%$ students by Class test and Assignment

Relevance: According to BW Education article (education.businessworld.in/article/Why-OnlineExaminations-Evaluation-And-Assessments-Are-Future-Of-Indian-Education-System-/22-05-2020-

192942/), some of the prominent universities like Jawaharlal Nehru University (JNU), Delhi University and Bangalore University have approved the conduction of exams online, and also OP Jindal University will be holding the year-end assessment online.

* The online provision to conduct examinations allows the convenience to set exam schedules, manage candidate validation and authentication, securely carry out exams, and monitor candidates online.

It guarantees data integrity by giving authorization only to approved personnel, online evaluation reduces the chances of delay in deceleration of result, students get instant marks during an online test like the MCQ test.

\section{Examination Evaluation:}

$50.00 \%$

Examination Evaluation

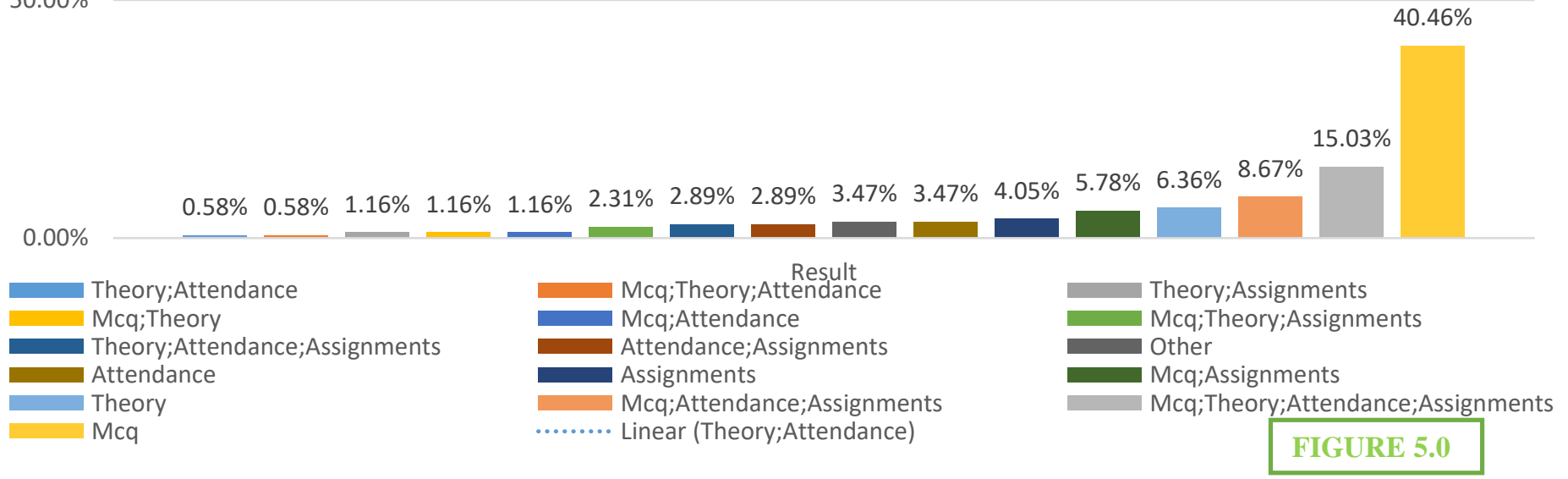

This graph shows the examination evaluation of students in the online mode of education

* In this graph $40.46 \%$ of student are evaluated by MCQ and Theory, $15.03 \%$ of student are evaluated by Theory and Assignment and 8.67\% students through MCQ, Theory and Attendance

* $6.36 \%$ of students are evaluated by Theory and Attendance, 5.78\% students are by MCQ and Assignment, and $4.05 \%$ are through Assignments only.

* $3.47 \%$ of students are evaluated by Attendance only, $2.89 \%$ students are evaluated through Attendance and Assignment and 2.31\% of students are by MCQ, Theory and Assignment.

The adaptive examination is like artificial intelligence and prepares the next question to be given to the student on its own. The evaluation parameters like assignments and attendance keep students engaged in attending the classes.

It makes the correction timeless and eases the work of the faculty.

\section{Source of revision:}




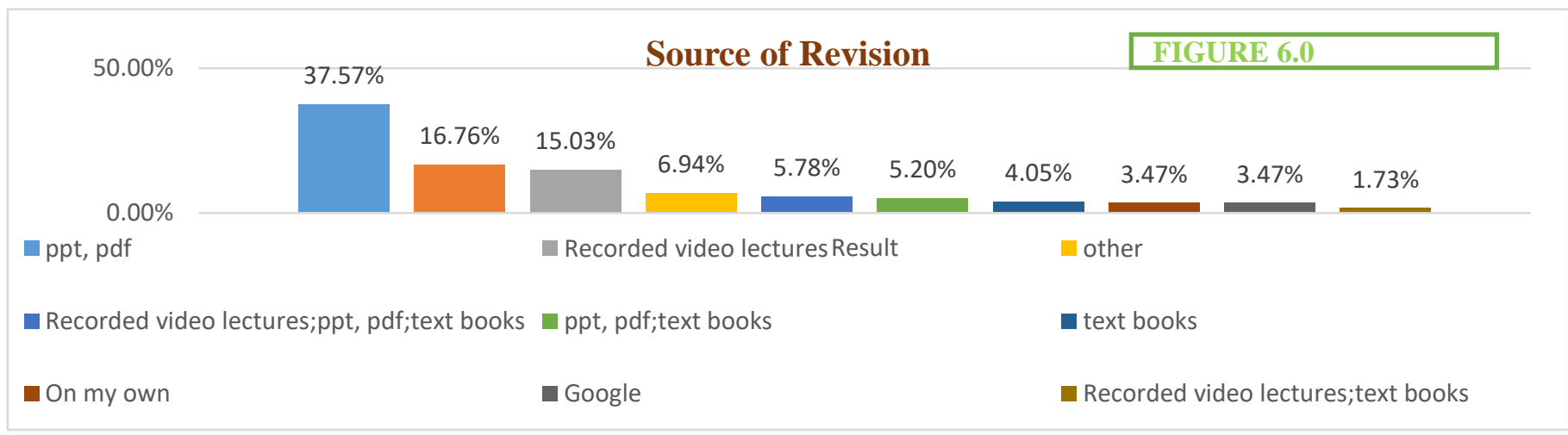

This graph tells us about the Source of Revision of the student in the online mode of the education system.

* By this graph $37.57 \%$ of students revise through Ppt and Pdf, $16.76 \%$ of students revise with help of Recorded Video Lecture, Ppt and Pdf and $15.03 \%$ of students revise with the help of Recorded Video Lecture only.

* $6.94 \%$ of students revise with the help of other means of revision source and $5.78 \%$ students revise with Recorded Video Lecture, Ppt, Pdf and Text Books.

* 5.20\% are revising with the help of Ppt, Pdf, and Text Books, 4.05\%students are revising with the help of Text Books only and $3.47 \%$ of students revise through on their revision source.

The online education system has vast sources of revision and this adds to the advantage of online education. Playing the recorded video lectures gets an added benefit to the students. Providing soft copies of textbooks and other study material. Videos related to learning are used to easily understand the concept.

\section{Query Handling Portal:}

This graph tells us about will students have a Queries Handling portal in the online mode of education.

* As the graph shows $57.50 \%$ of students have a queries handling portal.

* $42.20 \%$ of students don't have a queries handling portal. There are a lot of issues faced apart from teaching in the online education system and there are very few the query handling portals to resolve these issues.

* The companies which provide the service of the online education system to schools and colleges have their query handling portal where the issues are resolved in time.

* The portal only deals with the technical problems faced on the learning interface and can't help with the connectivity issues, etc.

The server crashes in between and there are no solutions apart from waiting which causes a gap in between.

\section{Change in Teaching Patent during COVID-19:}

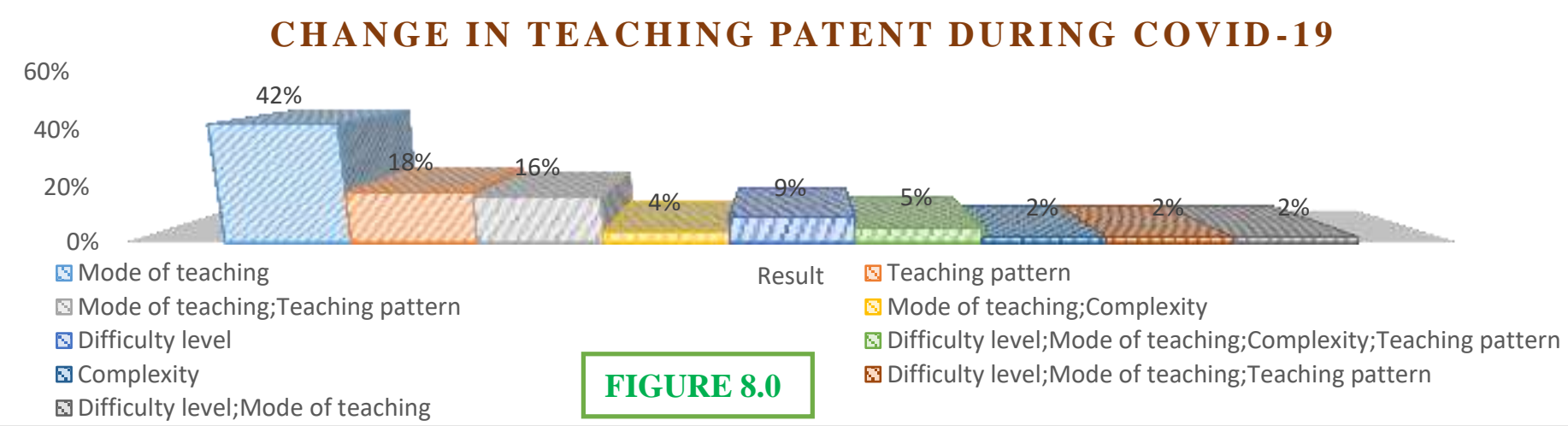


This graph is showing Only 9\% teacher feel difficulty in the mode of teaching like maybe most of the students has faced first-time online screen/ software/ Assignments/case studies/soft copy notes for study. 5\% of students had opted all are option changed which are quite less.

\section{Rate the challenges faced with technology:}

In this graph data is showing "Rate the challenges with technology" during the online studies...

$35 \%$ of teachers with (3 ratings) had faced moderate challenges with technology during online studies and $30 \%$ of a teacher with (4 Ratings) had faced high challenges and only $7 \%$ of students faced extremely high challenges faced with technology during online studies.

Some of the challenges faced by teacher:

* It's not easy for schools to keep up with the rapidly changing technology.

* Sometimes technology adds complexity to everything-support, teaching, learning, budgets, etc.

* This isn't accurate, precise, transparent, and communicated among all teachers/students.

* Faced challenges in calculate graphing problems and online Lab practical.

* Technical Issues like Network Problems, Internet dis-connectivity and software Issues, etc.

\section{Experience in Teaching Online:}

$69 \%$ of teacher are satisfied and $20 \%$ of teacher are showing Excellent results with teaching online and Only $11 \%$ of teacher are showing poor experience with online teaching due to some of the challenges like technical as well as Lack of alignment between technology, curriculum, and instruction

\section{Issue face by teachers in using online mode:}

This graph represents issues faced by teachers

* In this graph, $25 \%$ of issues are related to seriousness in studies and $22 \%$ issues are related to communication, also $25 \%$ faced communication and seriousness in studies problem.

* 9\% of issues are related with communication, seriousness in studies, and conducting of examination, $7 \%$ faced a problem related to conducting of examination only.

* 4\% are other issues faced by students and $7 \%$ issue are related to seriousness in studies and conducting of examination

The graph illustrated above shows the major issues and differences between online teaching and traditional teaching. Teachers have these major issues faced by the students about their seriousness towards studies and that there is a big communication gap between them which causes an understanding problem and thus increases the gap of education. There needs to be and proper communication medium so that there is no gap or miscommunication between them.

\section{How effective is online teaching:}

This graph represents how effective is online teaching on a scale of $1-5$

* As per this graph $49 \%$ of student rate Three (3) for online teaching on a scale of $1-5$ and $20 \%$ of student

\section{Experience in teaching online}

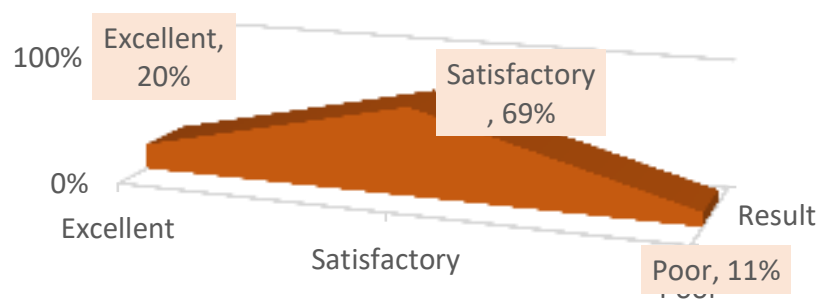

Issue faced in Teaching
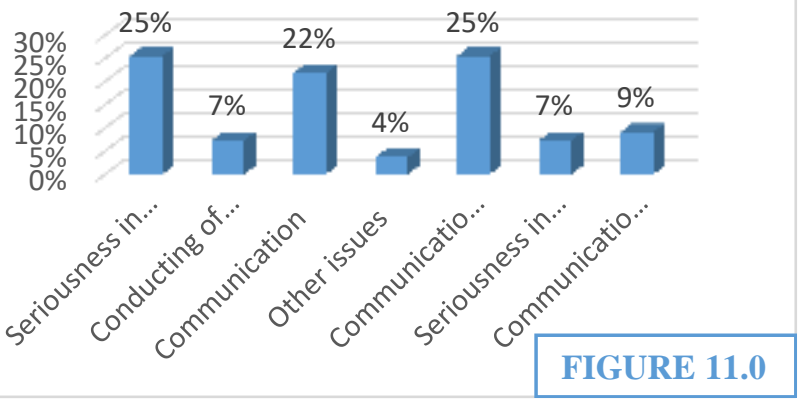

ON A SCALE OF 1 TO 5 HOW EFFECTIVE IS ONLINE TEACHING

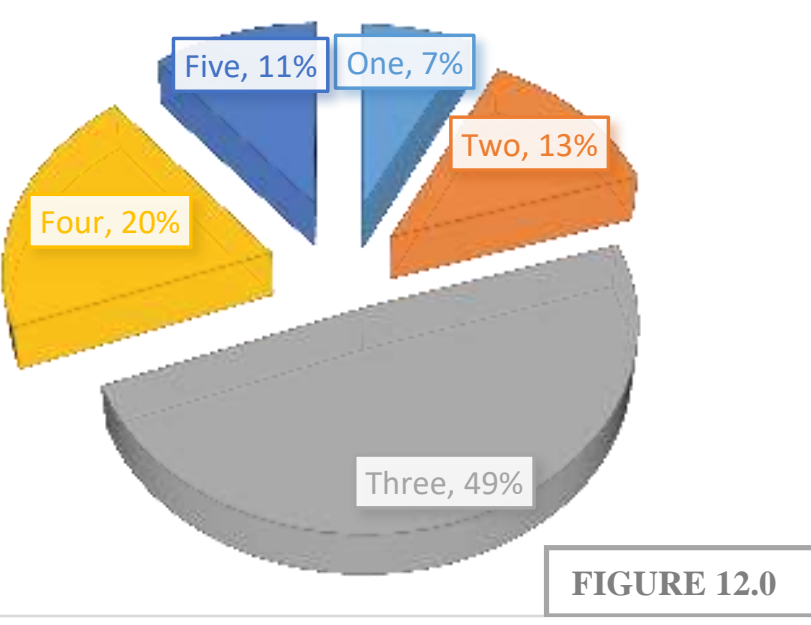


rate Four (4) for online teaching on a scale of 1-5.

* $11 \%$ of student rate Five (5) for online teaching on a scale of $1-5$ and $13 \%$ of student rate Two (2) for online classes.

* $7 \%$ of students gave One (1) rating for online classes.

\section{Problems faced apart from teaching:}

This graph represents the problem faced apart from teaching by teachers, below mention...

* 38\%teachers faced a problem related to Students Attendance and $24 \%$ of teachers faced problem-related with Internet Connectivity and Students Attendance.

* $18 \%$ of the teacher has Internet Connectivity Problem only and 5\% of teachers faced Administrative issues.

* $4 \%$ of teachers faced Administrative issues and Student Attendance and 5\% of teachers faced other issues, and also $5 \%$ of teachers face Internet Connectivity, Administrative issue and Student Attendance.

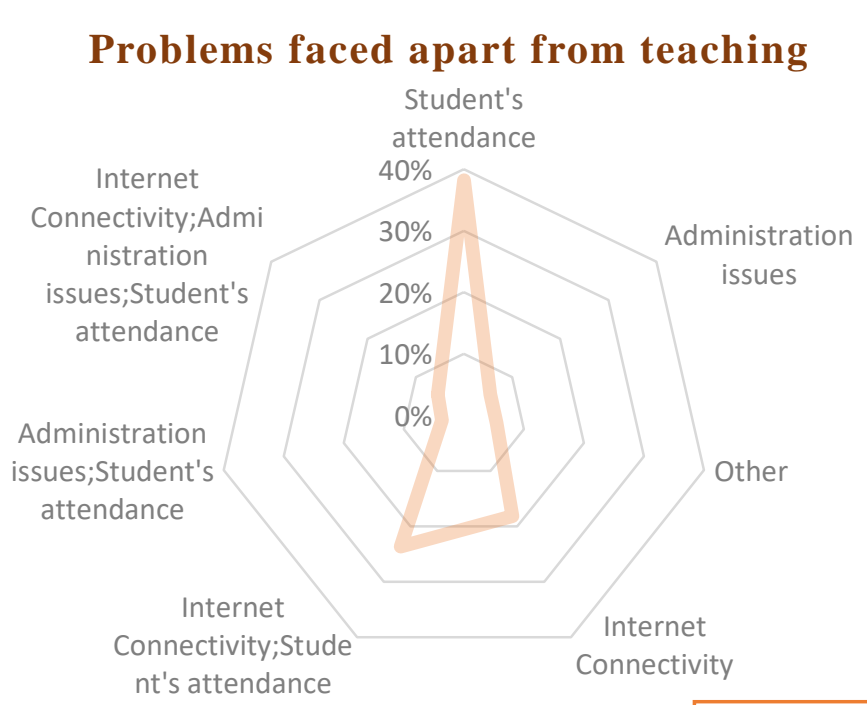

FIGURE 13.0

\section{Examination pattern in online mode:}

This graph represents the examination pattern in online mode

* As shown in the graph $36 \%$ of student have MCQ examination pattern, $18 \%$ of student have MCQ and Assignment examination pattern and $16 \%$ of student have only Assignment as an examination pattern

* 13\% have MCQ, Theory and Assignment examination pattern and $5 \%$ of student have theory only as examination pattern,

* 5\% of students have MCQ and Theory also 5\% of student have Theory and Assignment.

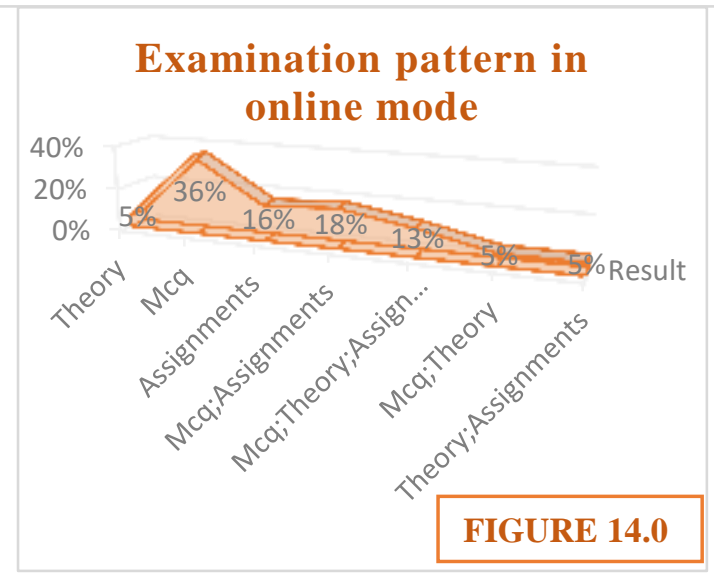

\section{Reference}

1. Teacher education scenario in India: Current problems \& concerns $\mid$ Goel $\mid$ Mier Journal of educational studies, trends and practices. (n.d.). Vol 10, No 1 (2020).

2. Computers and productivity: Evidence from laptop use in the college classroom. (n.d.). ScienceDirect.com | Science, health and medical journals, full text articles and books.

3. The role of information and communication technology (ICT) in mobilization of sustainable development knowledge: A quantitative evaluation. (2010, September 14). Digital Object Identifier System.

4. Technology-enhanced learning in developing nations: A review. (n.d.). Digital Object Identifier System.

5. Jewan Singh \& Vibhakar Mansotra. (n.d.). Factors affecting cloud computing adoption in the Indian school education system.

6. Shalni Gulati. (n.d.). Technology-enhanced learning in developing nations: A review. The International Review of Research in Open and Distributed Learning.

7. Mirghani Mohamed, Arthur Murray, Mona Mohamed. (2010, September 14). The role of information and communication technology (ICT) in mobilization of sustainable development knowledge: A quantitative evaluation. Discover Journals, Books \& Case Studies | Emerald Insight.

8. IJICT, International Journal of information sciences and technology, journals on computer science, electronics, electrical, engineering, mechanics, science and technology, mathematics and 
management. (n.d.). International Research Publication House, publishes journals on ComputerScience, Electronics, Mechanics, Physics, Chemistry, Mathematics and Management. 